\title{
The Empirical Study about Introduction of Stock Index Futures on the Volatility of Spot Market
}

\author{
Guiliang Tian, Huixiangzi Zheng
}

School of Business, Hohai University, China.

Email: xzll_xzbj@163.com

Received July, 2013

\begin{abstract}
April 16, 2010, China's first four Index Future contracts have been listed for trading in the stock exchange. Stock index futures are the world's fastest growing financial derivative products currently, and the research of them is of significance to the development of China's financial market. Therefore, it is particularly important to concern the market operation status of stock index future after its official listed. As we all know that there are linkage effects of the futures and spot, stock index futures market will have some impact on the spot market. Based on the above point, this study identified the Shanghai and Shenzhen 300 stock index futures market as the research object, focusing on what volatility affects the stock index futures have made on the spot market over the past 3 years. Through empirical findings, we can evaluate the operation conditions of stock index futures market objectively. This paper applies GARCH model mainly, and introduce dummy variables, collecting daily trading data between 16 April 2007 and 16 April 2013 on the spot market, and studies the impact of volatility on the spot market in-depth by empirical test. The results showed that over the past 3 years, introduction of stock index futures has reduced the volatility of the spot market which has brought a positive impact.
\end{abstract}

Keywords: Index Future; Spot Market; Volatility; GARCH Model

\section{Introduction}

Stock index futures, which are based on prior agreement between buyers and sellers, trade at a particular time in the future, in accordance with the prior agreement of both parties to engage in stock index trading shares of a standardized protocol agreement. April 16, 2010, our country's first financial derivatives - officially listed in Shanghai and Shenzhen 300 stock index futures trading. However, soon after its listing launched a vicious slump appears unilateral market conditions, driving the stock market also followed the collapse, and thus some scholars have suggested that the stock index futures market crash blame. Therefore, it is necessary to explore the introduction of stock index futures on the volatility of the spot market produce what kind of impact, in order to clarify whether the stock index futures is the "culprit."

According to the impaction of stock index futures on the spot market, scholars hold different views, and each view has a lot of theoretical research and empirical research support. Chan[1] on 1985-1987 Nikkei Stock Average daily trading data, with its day yield research object, through the establishment of GARCH model, the results found that the introduction of stock index futures on the spot market is not significantly affected. Anton- inus[2] based on FTSE 100 index tested a series of econometric model, including unit root test, vector error correction model, the establishment of such GARCH model and found that the introduction of stock index futures, increased the volatility of the spot prices stock, that is on the spot markets had a negative impact. Domestic scholars Tian-cai Xing and Ge Zhang[3] based on FTSE Xinhua A50 index futures, through the establishment of GARCH model, analyzes its launch on the CSI 300 stock index, the results found that the introduction of stock index futures slightly increases the volatility of the spot market, but this impact is very small. In 2010, they selected the CSI 300 index futures trading simulation data, through the establishment of GARCH model to test residual ARCH effects, etc., confirmed the launch of stock index futures on the volatility of the spot market is not greater impact. But because of the data from the simulation trading system, therefore the reliability of the conclusions still needs to be fastidious.

From the existing research, the current domestic and foreign scholars are mainly based on mature markets abroad to study the introduction of stock index futures on the spot market volatility impact on emerging markets such like our lack of research, especially in China the 
CSI 300 index futures launch date just over three years, the research scholars are mostly simulation-based transaction data, and conclusions vary. Therefore, this paper by choosing real transaction data were established before and after the introduction of index futures GARCH model, and the introduction of dummy variables, a series of empirical tests to explore CSI 300 stock index futures on the impact of volatility in the spot market, with certain practical significance.

\section{Research Methods}

\subsection{Sample Description}

This data is selected April 16, 2007 to April 16, 2013 in CSI 300 stock index futures contracts and the CSI 300 stock index daily closing price, that is listed on the CSI 300 stock index futures before and after the three years of the corresponding stock the daily closing price of the stock index of 1460 data. Among them, the futures data for the selection of the main contract data, namely the nearest month futures contracts of the daily closing price data. In the most recent month before the contract settlement date two or three days, month contract will be converted into the main contract, and then turned to the next nearest month futures contract closing data, and so on, can be a continuous set of stock index futures price time series. Data mainly comes from China Financial Futures Exchange, and the News Finance website. In accordance with the stock index futures launch time the data is divided into two stages, the first stage before the introduction of stock index futures, is from April 16, 2007 to April 16, 2010; second stage after the introduction of stock index futures, from April 16, 2010 to April 16, 2013.

\subsection{Data Processing}

Firstly, in order to eliminate heteroscedasticity, respectively futures price and spot price series sequence logarithm.

Assuming that the trading day closing price of a futures contract and the spot index closing price are denoted as $P_{t}$ and $Q_{t}$, then the natural logarithm of futures contract price series expressed as $F_{t}=\ln P_{t}$, its logarithmic rate of return is $\Delta F_{t}=\ln P_{t}-\ln P_{t-1}$, the natural logarithm of stock price series expressed as $S_{t}=\ln Q_{t}$, its logarithm yields expressed as

$$
\Delta S_{t}=\ln Q_{t}-\ln Q_{t-1} .
$$

The study object of this paper is the log return of stock index futures and spot price rate.

\subsection{Model Selection}

Existence of financial time series data aggregation and volatility heteroscedasticity, OLS regression model is the assumption that "homoscedasticity", therefore, in the study when the price volatility of financial products, widely used heteroscedasticity model is the most widely used in the 1982 Engle proposed autoregressive conditional heteroskedasticity model (ARCH model), Bollerslev deepened the ARCH model, the generalized autoregressive conditional heteroskedasticity model (GARCH model), GARCH model can well reflect the aggregation of price volatility, in the previous literature, the widespread use of GARCH $(1,1)$ model reflects the aggregation of financial products.

This paper uses the GARCH $(1,1)$ model stock index futures on the volatility of the spot market, and the introduction of dummy variables in the conditional variance to reflect the CSI 300 stock index futures on the impact of the stock market volatility, Before the introduction of stock index futures, $\mathrm{D}=0$, after the introduction of stock index futures $\mathrm{D}=1$. The $\operatorname{GARCH}(1,1)$ model with the following:

The mean equation: $y_{t}=\gamma x_{t}+\mu_{t}$

The conditional variance equation:

$$
\sigma_{t}^{2}=\omega+\alpha \mu_{t-1}^{2}+\beta \sigma_{t-1}^{2}
$$

The GARCH $(1,1)$ model was respectively established for the different stages, the model does not add dummy variables.

\section{Empirical Tests}

We need to know the basic statistical characteristics of the return series of CSI 300 index before the empirical test.

From the Figure 1, we can clearly see that this series has the cluster effect which most economic sequence possesses. It means that the current price effected by the prices of the previous period, which we call the ARCH effect.

\subsection{The Volatility Analysis of the Spot Price Three Years before the Launch of CSI 300 Index Futures}

1) Do the ADF test of return series of the stock index

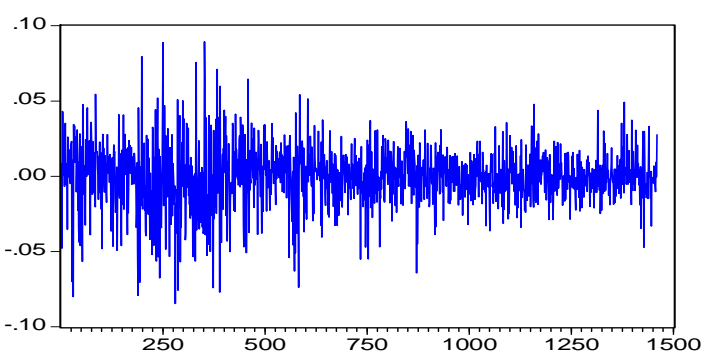

Figure 1. The return's volatility of stock index in whole sample period. 
First we do the ADF test of return series of the stock index, the test result is as follows:

From the Table 1, we can see that the stationary test results are significant, thus rejecting the null hypothesis that the return series is stationary. Then we establish ARMA model.

2) Establish ARMA model

a) Determine the value of $p$ and $q$

Before the establishment of ARMA model, we should see autocorrelation and partial autocorrelation chart of the daily return series of Shanghai and Shenzhen 300 index three years before the introduction of futures. The figure appears in several places which autocorrelation and partial autocorrelation functions are significant, therefore we cannot determine the value of $\mathrm{p}$ and $\mathrm{q}$ directly. Then we draw support with the AIC and SC principle by imitating ARMA model within a 5-order.

By comparing the value of AIC and SC, we can build ARMA(2,3) model.

b) Build ARMA(2,3) model

The following table is the output of ARMA $(2,3)$.

As we can see from Table 2, the results of model estimation are good. At the $1 \%$ confidence level, in addition to the constant term, the $\mathrm{P}$ value of all the coefficients are less than $1 \%$, passing the test, $\mathrm{R} \wedge 2=50.20 \%$. Value of DW is around 2 which has no autocorrelation. At this point, we remove the constant term. The expression of ARMA $(2,3)$ model is as followings:

Table 1. The ADF test results.

\begin{tabular}{cccc}
\hline \multirow{2}{*}{ ADF test } & t-Statistic & Prob.* $^{*}$ \\
\cline { 3 - 4 } & 1\% level & -26.3974 & 0.0000 \\
\hline $\begin{array}{c}\text { Significance } \\
\text { level }\end{array}$ & $5 \%$ level & -1.9412 & 0.0000 \\
& $10 \%$ level & -1.6164 & 0.0000 \\
\hline
\end{tabular}

Table 2. Output of ARMA (2,3).

\begin{tabular}{ccccc}
\hline Variable & Coefficient & Std. Error & t-Statistic & Prob. \\
\hline C & $-5.72 \mathrm{E}-06$ & $1.31 \mathrm{E}-05$ & -0.4368 & 0.6624 \\
$\mathrm{AR}(1)$ & -1.0280 & 0.0086 & -118.93 & 0.0000 \\
$\mathrm{AR}(2)$ & -0.9681 & 0.0086 & -112.03 & 0.0000 \\
$\mathrm{MA}(1)$ & 0.0701 & 0.0074 & 9.4621 & 0.0000 \\
$\mathrm{MA}(2)$ & -0.0499 & 0.0078 & -6.4055 & 0.0000 \\
$\mathrm{MA}(3)$ & -0.9817 & 0.0066 & -149.81 & 0.0000 \\
\hline
\end{tabular}

$$
\begin{aligned}
R_{1 t}= & -1.0280 R_{1 t-1}-0.9681 R_{1 t-2}+0.0701 u_{t-1} \\
& -0.0499 u_{t-2}-0.9817 u_{t-3}+\mu_{t}
\end{aligned}
$$

c) Do the ARCH Tests of ARMA $(2,3)$ model

Before the establishment of GARCH model, we need to test the ARCH effect of residuals series. We use the method of ARCH-LM test. The result is as follows:

The result of ARCH-LM test is significant, indicating that we can establish GARCH $(1,1)$ model.

3) Build GARCH model

a) Build ARMA(2,3)-GARCH(1,1) model

The specific form of ARMA (2,3)-GARCH (1,1) model is as follows:

Mean equation:

$$
\begin{aligned}
R_{1 t}= & -1.0053 R_{1 t-1}-0.9745 R_{1 t-2}+0.0342 u_{t-1} \\
& -0.0151 u_{t-2}-0.9824 u_{t-3}+\mu_{t}
\end{aligned}
$$

Variance equation:

$$
\sigma_{t}^{2}=0.00000538+0.0634 \mu_{t-1}^{2}+0.9279 \sigma_{t-1}^{2}
$$

As we can see from Figure 2: the current yield of the spot index will be effected by yield of its lagged one period at a strength of -1.0053 , by yield of its lagged two period at a strength of -0.9745 . The current volatility will be affected by the volatility of previous period at a strength of 0.9279

\begin{tabular}{|c|c|c|c|c|}
\hline & Coefficient & Std. Error & z-Statistic & Prob. \\
\hline \multicolumn{5}{|c|}{ Mean equation } \\
\hline $\operatorname{AR}(1)$ & -1.0053 & 0.0060 & -167.76 & 0.0000 \\
\hline $\mathrm{AR}(2)$ & -0.9745 & 0.0052 & -186.64 & 0.0000 \\
\hline MA(1) & 0.0342 & 0.0042 & 8.2244 & 0.0000 \\
\hline MA(2) & -0.0151 & 0.0061 & -3.4693 & 0.0035 \\
\hline MA(3) & -0.9824 & 0.0033 & -295.86 & 0.0000 \\
\hline \multicolumn{5}{|c|}{ Variance equation } \\
\hline C & 5.38E-06 & $2.74 \mathrm{E}-06$ & 2.4586 & 0.0302 \\
\hline $\operatorname{RESID}(-1)^{\wedge} 2$ & 0.0634 & 0.0126 & 5.0356 & 0.0000 \\
\hline GARCH(-1) & 0.9279 & 0.0135 & 68.6766 & 0.0000 \\
\hline
\end{tabular}

b) Do the ARCH-LM test of residuals series.

Table 3. ARCH-LM test of residuals series.

\begin{tabular}{cccc}
\hline F-statistic & 4.7359 & Probability & 0.0002 \\
\hline Obs*R-squared & 23.1165 & Probability & 0.0003 \\
\hline
\end{tabular}

Table 4. Output of GARCH model. 
Table 5. Output of ARCH-LM test.

\begin{tabular}{cccc}
\hline F-statistic & 0.3319 & Probability & 0.8938 \\
\hline Obs*R-squared & 1.6697 & Probability & 0.8927 \\
\hline
\end{tabular}

The value of $\mathrm{P}$ is 0.8938 , thus the ARCH effect of residuals no longer exist, which indicates that ARMA $(2,3)$-GARCH $(1,1)$ model is fully fitted at the return series of CSI 300 stock index.

\subsection{The Volatility Analysis of the Spot Price Three Years after the Launch of CSI 300 Index Futures}

This section of the concrete steps is as above, so we will not repeat. Establish GARCH model of returns on Spot Index three years after the introduction of index futures like follows:

Mean equation:

$$
R_{2 t}=-0.5013 R_{2 t-1}+\mu_{t}
$$

Variance equation:

$$
\sigma_{t}^{2}=0.000014+0.0477 \mu_{t-1}^{2}+0.9036 \sigma_{t-1}^{2}
$$

As we can see: the current yield of the spot index will be effected by yield of its lagged one period at a strength of -0.5013 . The current volatility will be effected by the volatility of previous period at a strength of 0.9036 .

\subsection{Differences Analysis}

Firstly, we draw the volatility chart of spot price in the whole sample period.

From the figure, we can easily see that the volatility of stock price has weakened three years after the introduction of stock index futures. So we can preliminary judge that the introduction of stock index futures reduces the volatility of the spot market.

Next, we will build a GARCH model based on the whole sample interval, and introduce dummy variables. Do positive and negative test of dummy variable coefficients, and see if it passed the examination to verify whether the introduction of stock index futures reduces the volatility of the spot market. Establishing revise GARCH model likes follows:

Mean equation:

$$
\begin{aligned}
R_{t}= & -0.5431 R_{t-1}+0.2787 R_{t-2}-0.2774 u_{t-1} \\
& -0.7628 u_{t-2}+0.0499 u_{t-3}+\mu_{t}
\end{aligned}
$$

Variance equation:

$$
\begin{aligned}
\sigma_{t}^{2}= & 0.00000698+0.0345 \mu_{t-1}^{2} \\
& +0.9581 \sigma_{t-1}^{2}-0.00000378 \omega
\end{aligned}
$$

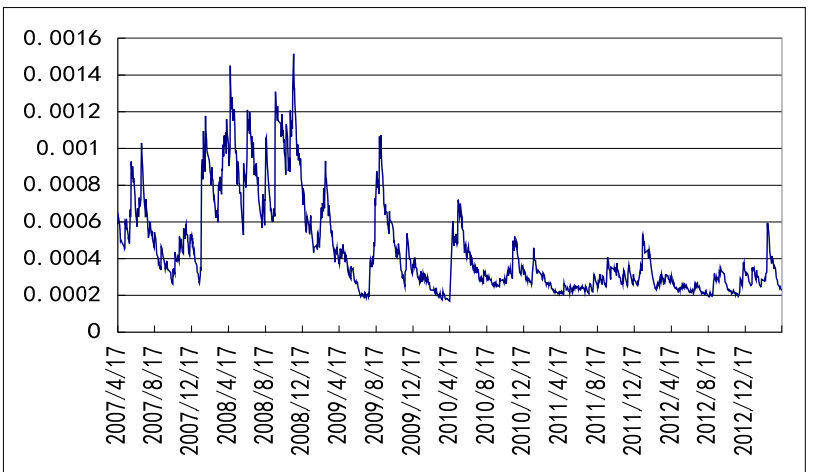

Figure 2. Volatility of whole sample period.

As we can see: the current yield of the spot index will be effected by yield of its lagged one period at a strength of -0.5431 , by yield of its lagged two period at a strength of 0.2787 . The current volatility will be affected by the volatility of previous period at a strength of 0.9581 .

The most important, the coefficient of dummy variable is negative, and passed the test, indicating that the introduction of stock index futures reduces the volatility of the spot market, which made a positive impact on the spot market.

\section{Conclusions and Recommendations}

This article studies the impact of the introduction of stock index futures on the volatility in the spot market by establishing GARCH $(1,1)$ model, and the introduction of dummy variables, and found the stock index futures has a slight decrease on the volatility of spot market volatility. In order to promote the development of the stock index futures market, reduce the negative impact to a minimum of the future futures on the spot market may, we propose the following comments and suggestions, mainly discussed from the two aspects include continue to improve the spot market and strengthen the risk supervision and management of the futures market.

\subsection{Improve the Spot Market Continually}

The development of stock index futures markets takes the developed spot market as a precondition. Although China's stock market has been so close to the international advanced level in the technical facilities, forming the aspect of market size, marketing supervision system, information disclosure is also far behind, therefore, we should strengthen the standardization of the spot market, and promote the sharing and coordination management of the stock market and stock index futures market.

\subsection{Strengthen Risk Oversight and Management of the Futures Market}

Volatility is an important indicator to measure market 
risk, the size of volatility determines the size of the market, although the empirical test the introduction of stock index futures in our country did not increase the volatility of the spot market, because of the stock index futures itself has a larger market risk, in order to continue to promote the development of the futures market, we still need to strengthen risk management of the stock index futures. Combined with the actual situation of China's market, we should mainly make the following recommendations: A. Perfect market investors, strengthen institutional investors, leading the reasonable and health investment philosophy in the market. For now, mainly take the insurance companies, fund companies, securities companies as the main body of hedging, and encourage the arbitrage behavior of the market, reduce systemic risk along with promote the price discovery function of futures markets yield well and effectively. B. Improve the management of various accounts. Since the futures implement the policy of margin, it is necessary to strengthen the supervision of the trading margin and clearing margin, implement the daily free debt settlement system. At the same time, we also need to continue to strengthen the management of the large positions system and forced open system as well as take effectively care of risk reserves, etc., and adopt international advanced real-time monitoring technology to effectively circum- vent the stock index futures market risks. C. Timely and targeted introduce the institutional arrangements, improve relevant laws and regulations, make the regulatory abilities and adhere adapt the speed of development in order to laid a good foundation for the entire market's healthy and stable development.

\section{Acknowledgements}

This study was funded by the National Natural Science Foundation of China (Grant No. 41001377, 51279058)

\section{REFERENCES}

[1] Chan and Karolyi, "Introduction Volatility in the Stock Index and Stock Index Futures Review of Financial Studies,” Vol. 4, No. 3, 1991, pp. 657-684.

[2] Antoninus, "Return and Volatility Dynamics in the FT-SE 100 Stock Index and Stock Index Futures Markets,” Journal of Futures Markets, Vol. 15, No. 4, 1995, pp. 457-488.doi:10.1002/fut.3990150405

[3] Xing Tiancai and Zhang Ge, “The Empirical Study about Impact of stock index futures on the spot market - Based on the analysis of the FTSE Xinhua A50," Research on Financial and Economic Issues, Vol. 4, No. 7, 2009, pp. 83-88. 